\title{
Stopping of transport vehicles using the power electromagnetic pulses
}

\begin{abstract}
Operation of electrical and electronic systems can be disturbed by the influence of natural or artificially generated electromagnetic pulses $(E M P)$. In this connection for many years people successfully developed means for generating the power EMP also in the form of weapon systems. Potential targets can be the important elements of critical infrastructure, military systems or transport vehicles, for example if necessary stopping the moving vehicle, as well as vehicles, which penetrated to vicinity of the protected object or stopping of vehicles at control posts.
\end{abstract}

Streszczenie. Praca systemów elektrycznych I elektronicznych może być zakłócana przez generowane impulsy elektromagnetyczne. Takie impulsy mogą też służyć jako broń przeciw systemom militarnym w tym także pojazdom. Możliwości zatrzymania ruchu pojazdu za pomocą impulsów elektromagnetycznych

Keywords: Electromagnetic Pulse, Direct Energy Weapons, High Power Microwave, Non-Lethal Weapons. Słowa kluczowe: broń elektromagnetyczna, impulsy elektromagnetyczne

\section{Introduction}

The development of automotive technology is coupled with the increase of electronic components, which are sources of electromagnetic interference (EMI) and also in terms of electromagnetic susceptibility (EMS) their activities may be disrupted by electromagnetic interference from the surrounding sources. The measurement of EMI and testing of EMS are performed for automobiles and their electronic components and subsystems in accordance with European Directive 2006/28/EC and set of standards ISO 11451 (Road vehicles - Vehicle test methods for electrical disturbances from narrowband radiated electromagnetic energy) and ISO 11452 (Road vehicles - Component test methods for electrical disturbances from narrowband radiated electromagnetic energy). Within the automotive technology is also required follow the set of standards ISO 7637 (Road vehicles - Electrical disturbances from conduction and coupling) and ISO 10605 (Road vehicles Test methods for electrical disturbances from electrostatic discharge). Other legislative documents relating to the issue of electromagnetic interference vehicles and boats are documents published by International Electrotechnical Commission CISPR 12 (Vehicles, boats and internal combustion engines - Radio disturbance characteristics Limits and methods of measurement for the protection of off-board receivers) and CISPR 25 (Vehicles, boats and internal combustion engines - Radio disturbance characteristics - Limits and methods of measurement for the protection of on-board receivers). Czech versions of these documents have designation CSN EN 55012 a CSN EN 55025.

Critical electronic components especially the control unit in vehicles are very good protected against the EM interference (shielding, filtration). Due to the physical and economic constraints, these measures correspond to the levels of EM environment which may exist in the surroundings of vehicles. For vehicles which have been deliberately exposed to the electromagnetic field it can cause disruption of engine functions (a temporary failure self-renewable failure, failure which require user intervention or repair service provided or failure which causes physical damage and damage to sensitive electronic components). Stopping the motor may be caused by faulty actions of the control unit (disruption of the internal microprocessor), when usually occurs that the motor immediately stops. Another case is when the control unit operates correctly, but due to incorrect signals from the sensors engine performance may be reduced, may be formed failures in the operation and subsequent motor blockage. In terms of EMS the testing of vehicle components is carried using the electromagnetic field with test level of $30 \mathrm{~V} / \mathrm{m}$. Some of car manufacturers use test level up to $200 \mathrm{~V} / \mathrm{m}$. The electromagnetic directed energy weapons are able to generate EM field with intensity up to $300 \mathrm{kV} / \mathrm{m}$.

\section{Direct Energy Weapons}

Direct energy weapons (DEW) include laser weapons, particulate weapons, weapons operating in band of radio waves and microwaves. In terms of focus contribution are also important DEW which use pulsed electromagnetic field in band of radio waves (DEWRF- Radio Frequency, hundreds of $\mathrm{kHz}$ to $1 \mathrm{GHz}$ ) and in band of microwaves (DEWM- Microwave, $1-300 \mathrm{GHz}$ ). These weapons can cause disruption action of electronic devices, damage or destruction of circuits, in practice e.g. damage to computers, opening/closing electronic valves, damage to data, disruption of communication, loss of control and power interruption. The electromagnetic weapons DEWRF and DEWM are further divided into the narrowband (using HPM- High Power Microwave) and wideband (UWB- Ultra Wide Band). Wideband EMC weapons emit radiation in a wide frequency range, but with a low energy density. These devices are suitable where it is not possible to accurately identify the characteristics of the target - especially its working frequencies. In contrast narrowband EMC weapons emit pulses at the individual frequencies with very high power. Impact on the target is very effective, because impulse resonates with the known frequency of the attacked device.

DEW usually consists of a primary energy source (eg. the capacitive battery), generator (magneto-hydrodynamic generator, explosively pumped generator), fast switching element (for wideband DEW) or power vacuum tubes (for narrowband $\mathrm{DEW}$ ) and antenna. The impulse source transforms accumulated energy to high power electric pulse with duration in units of nanoseconds. This pulse then produces a beam of electrons with energies up to $400 \mathrm{kV}$, $10-60 \mathrm{kA}$ in the source of microwave radiation. This energy is radiated by the directional antenna.

HPM electromagnetic guns can be used at a distance of several tens of meters to hundreds of kilometres depending on the carrier. These weapons can be constructed as warheads on missiles, artillery shells, portable, mobile or 
stationary equipment. For example the reach of the mobile HPM weapon system Ranets-E (Russia) (Fig. 1) is up to 40 $\mathrm{km}$ (intensity of electric field of $1 \mathrm{kV} / \mathrm{m}$ ) while at a distance of $2 \mathrm{~km}$ it generates EM field with an intensity of $19 \mathrm{kV} / \mathrm{m}$.

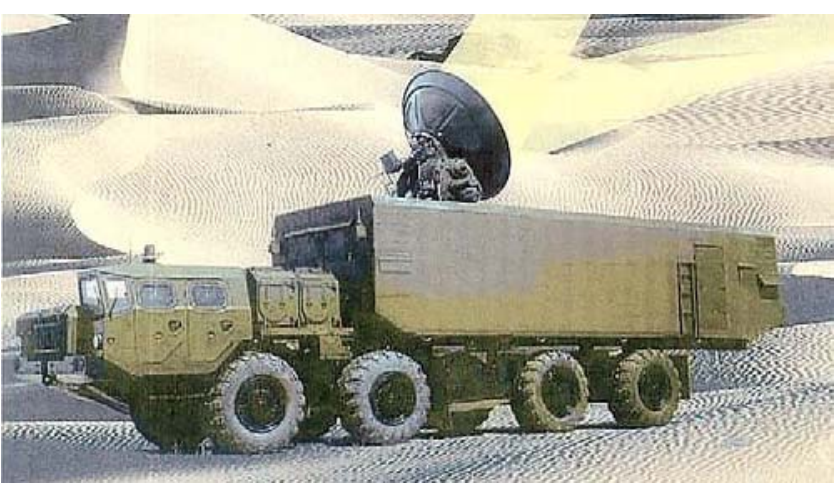

Fig. 1 HPM weapon system Ranets-E [1]

In the world the research and development of electromagnetic weapon is engaged a wide number of governmental and private organizations, including universities. A significant position in this field they are primarily USA, Russia and China. Other countries such as Germany, France, Australia, India, Japan, Israel, South Korea is also concerned with the issue of HPM in the long time. Czech Republic was also represented in this issue in special panels of as part of NATO Science and Technology Organization, such as Tactical Implications of High Power Microwaves, HPM Threat to Infrastructure and Military Equipment, HPM and Directed Energy Weapons. Research and development conducted in the Czech Republic for example in the field of high power of microwaves generators or the protection of military facilities against the effects of power electromagnetic field, under the direction of VTUPV Vyskov.

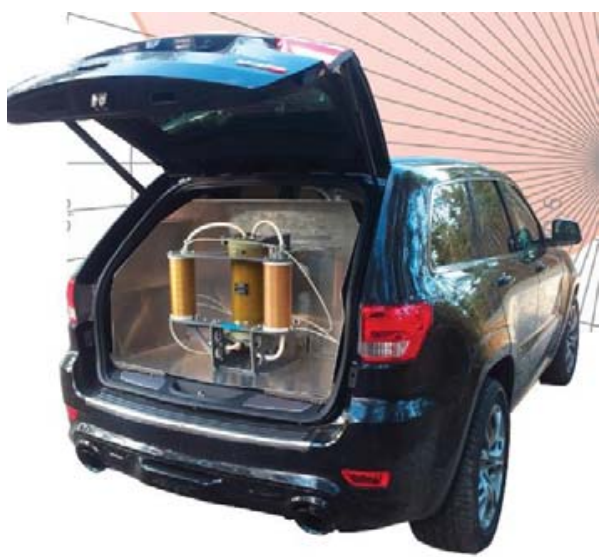

Fig. 2 The system stopping of vehicles HPEMcarStop [2]

The electromagnetic means for stopping of vehicles

Among significant manufacturers HPM technology include for example the company Diehl BGT Defence $\mathrm{GmbH} \&$ Co., Roethenbach/Pegnitz, Germany, which in the field stopping of vehicle produces HPEM (High Power Electro Magnetics) effectors in the form of systems with the designation HPEMcarStop and HPEMcheckPoint. System HPEMcarStop (Fig. 2) can be used e.g. for activities the police, army, special operations units or protection of important events (eg. the Olympic Games). The system is designed so that EMP operates on the target vehicle from its front side, it means that the EMP generator is installed on a platform in the rear part the vehicle (Jeep Grand Cherockee). It allows:
- stopping the engine stationary or slow moving vehicles (e.g. vehicles used for bank robberies, scrutineering drug or within the needs of detention persons),

- stopping speeding vehicles,

- protection of convoys (reduce the risk of attack from other vehicles - collision, shooting), vehicle HPEMcarStop goes as the last and maintains other vehicles at a distance.

HPEMcarStop was successfully tested in the tests with more than 60 different types of vehicles and allows stopping the target the vehicle at a distance of 3 to $15 \mathrm{~m}$ with more than $75 \%$ success rate.

System HPEMcheckPoint (Fig. 3) from the same manufacturer is designed the stopping of vehicles at checkpoints and important objects (e.g. the critical infrastructure). It combines a system HPEMcarStop with another source HPEM which is located on the trailer. Fig. 4 shows a possible scenario of system deployment when the target vehicle is exposed to the EMP in position 2 (HPEM in the trailer) and other HPEM device in the vehicle is designed as a backup.

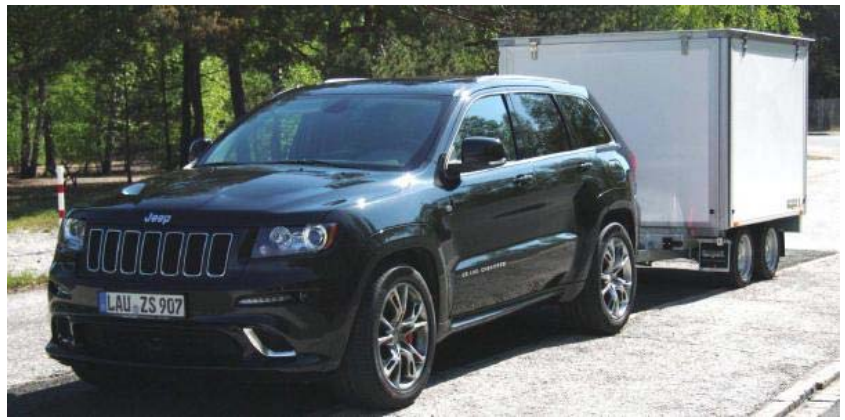

Fig. 3 The system stopping of vehicles HPEMcheckPoint [3]

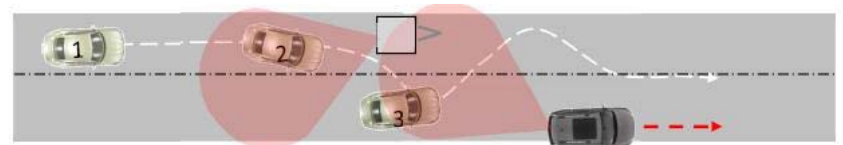

Fig. 4 The scenario applications HPEMcheckPoint [3]

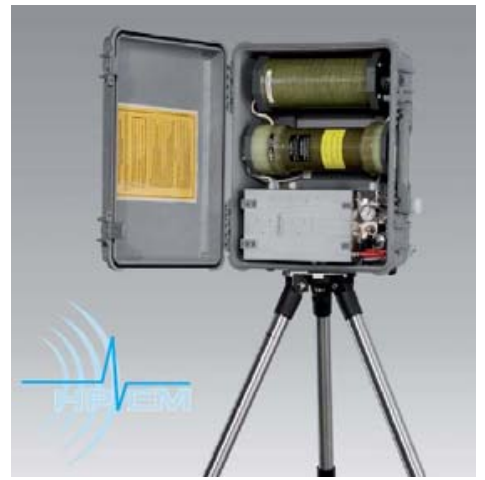

Fig. 5 System for protecting buildings and persons HPEMcase [4]

Another device that can be used alternatively to stop the vehicle is a portable, battery system HPEMcase (Fig. 5), whose primary destination is the deactivation of electronics (computer equipment, data centres, eavesdropping devices, security alarm systems, etc.). In the framework the protection of objects the system can be used at points of control the entry of persons (against the suicide bombers or intelligence technology). The maximum intensity of the EM field is $160 \mathrm{kV} / \mathrm{m}$ or $300 \mathrm{kV} / \mathrm{m}$ with the reflector at a distance of $1 \mathrm{~m}$ from the antenna. 
British company e2v (Chelmsford, England) within its manufacturing program, which is also focused on microwave devices for military and civilian purposes, this company offers a system RF Safe Stop (Fig. 6). This system allows by installation terrestrial and naval deployment. The system is intended to stopping the vehicles within the control points, the protection of convoys and other relevant actions. This system can use the marine police for the protection entrances to harbors or stopping the motor vessels. The device has a weight of $350 \mathrm{~kg}$ and a working distance up to $50 \mathrm{~m}$. In practice it is installed e.g. on vehicles Nissan Nevara or Toyota Land Cruisers. The device is capable of operating in a total time of 12 minutes on one charge, however, the effect of EMP with length of 3 $s$ is sufficient for stop the vehicle.

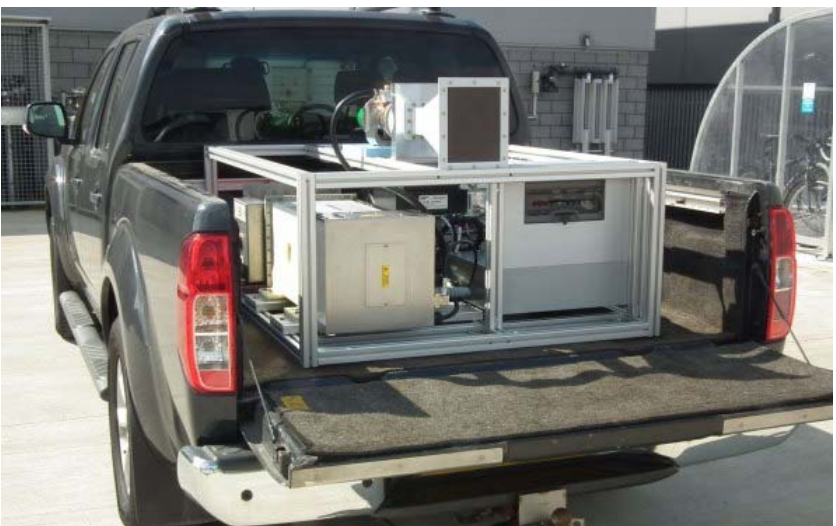

Fig. 6 Installing the system RF Safe Stop [5]

Deployment of the system RF Safe Stop in stationary installation on the control point shown in the Fig. 7. The motors of vehicles are capable of re-operation after a forced stopping, but in some cases is required disconnect the battery. The device does not have a negative effect on people's health.

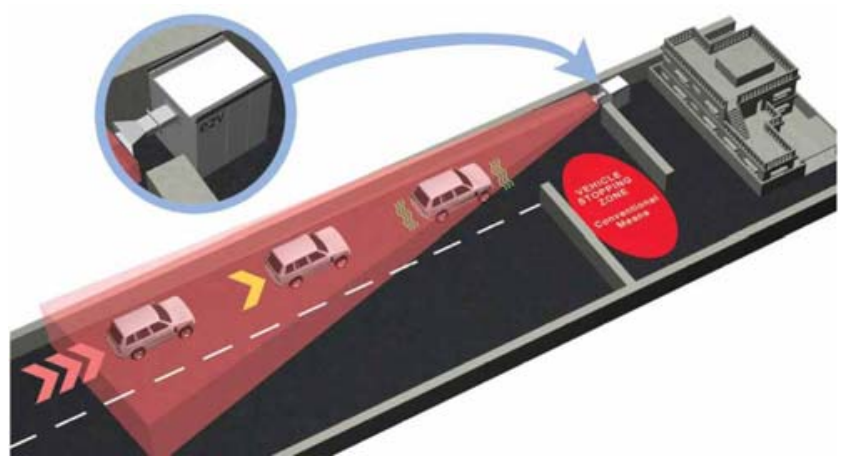

Fig. 7 Application of the system RF Safe Stop [5]

Other manufacturers which produce similar devices include company Eureka Aerospace (Pasadena, California, USA). This company is engaged the use of microwave and RF technology [6]. The system with the designation HPEMS (High-Power Electromagnetic System) is intended to stopping the vehicles, ships and elimination of the electronic triggers of improvised explosive devices. This system ensures protection of important objects (representative offices, embassies and consulates, military buildings, drilling platforms, harbors etc.). Basis equipment consists of 16 degree of Marx generator whose working distance is given up to $200 \mathrm{~m}$, the frequency of $350 \mathrm{MHz}-1.35 \mathrm{GHz}$, energy EM fields $20 \mathrm{kV} / 50 \mathrm{~m}$.
Similarly as the development of HPEMS of company Eureka Aerospace been implemented in cooperation with the armed forces, in this case the USMC (United States Marine Corps). A number of other elements of the armed forces is also involved on the development of equipment that uses the EMP as a weapon instrument. Significant role in the US Armed Forces constitutes JNLWD - Joint NonLethal Weapons Directorate, which controls, supports and coordinates research and development in the field of nonlethal weapons. Within the framework of its activities is also involved in the development of means to stopping of vehicles and ships (in cooperation with the L-3 Electron Devices, USA), which include the systems of multifrequency/radio-frequency Vehicle Stopper (Fig. 8), radio frequency Vessel Stopper or Non-Lethal Unmanned Aerial Vehicle High Power Microwave Payload. The system Vehicle Stopper is designed primarily for the protection of the army and it is expected deployment on the access points, checkpoints, at roadblocks or for mobile patrols. The system will be designed as a portable simultaneously are developed systems for stopping the motor vessels that will be installed on a ship or on air pilotless devices.

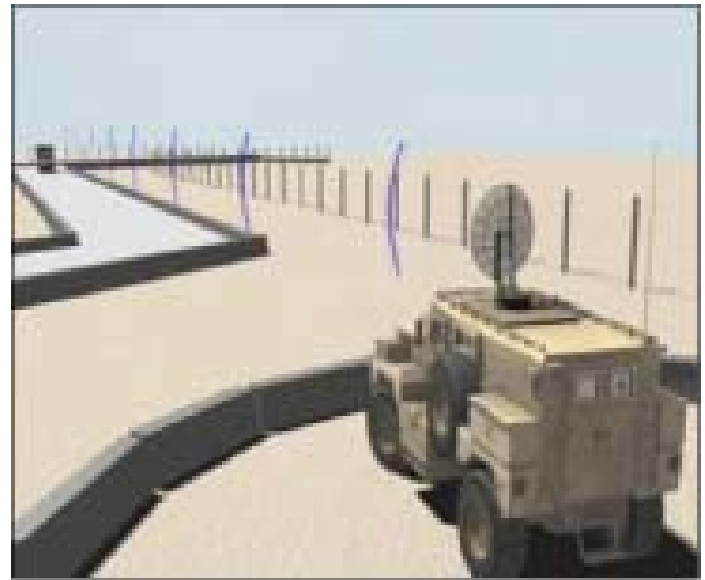

Fig. 8 Vehicle Stopper [7]

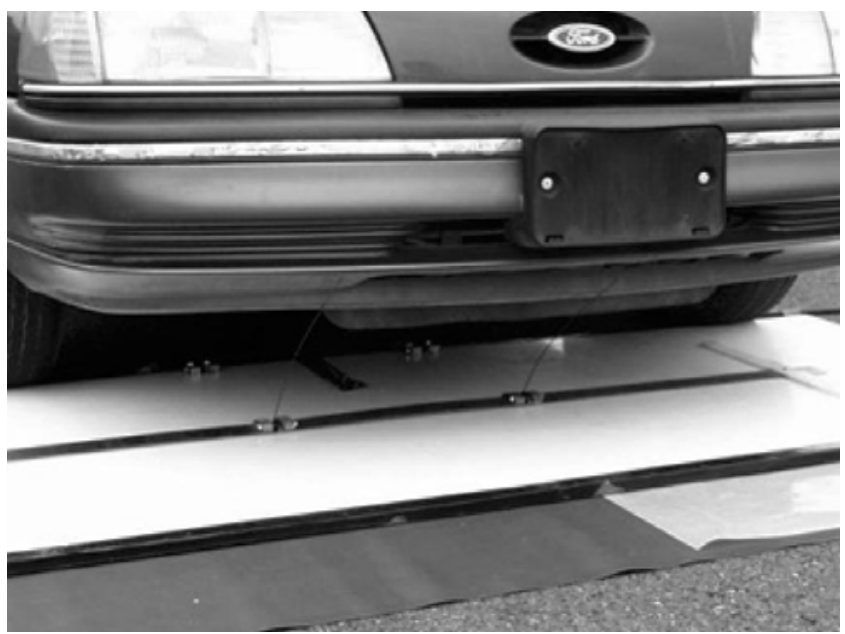

Fig. 9 Electrical Vehicle Stopper [8]

In the past the company Army Research Laboratory also dealt of similar problems, but with a different approach to the penetration of the EMP. They developed system EVS (Electrical Vehicle Stopper) (Fig. 9) in collaboration with the National Institute of Justice. This system used generators $(180 \mathrm{kV})$ instead of using the directional antennas. These generators are connected to spring electrodes which have been installed in the plates on the roadway. When passing the vehicle via the air hoses the voltage is connected to the 
electrodes and after the contact or approximation to the frame and motor of the vehicle is disturbed operation of motor. [8]

\section{Conclusion}

Vulnerability of automobiles to the intentional effect of electromagnetic pulses related to intensity of pulses which are applied to the electronic components and systems. The first electronic components was began to install into the vehicles in the 60 s of the last century and presently have modern vehicles up to 100 microprocessors which control most of their functions. About the technology which uses the power electromagnetic pulses for the stopping of vehicles is a great interest especially from the police security forces corps (stop the speeding of vehicles) and army (support the activities of checkpoints, protecting convoys and defense infrastructure). At present the EMP technology to the stopping of vehicles are manufactured and deployed in practice. The significant manufacturers include companies e.g. Diehl, Eureka Aerospace or E2V, where a number of military research organizations are involved in the development of these devices. In the Czech Republic research and development was conducted for example in the field of high power microwave generators or the protection of military facilities against the effects of power electromagnetic fields with the possibility of using for stopping the getaway of vehicles and prevent the entrance into protected areas.

\section{Acknowledgments}

The work was performed with financial support by Internal Grant Agency of Tomas Bata University under the project No. IGA/FAI/2015/043; further it was support of research project NPU I No. MSMT-7778/2014 by the Ministry of Education of the Czech Republic and also by the European Regional Development Fund under the Project CEBIA-Tech No. CZ.1.05/2.1.00/03.0089.

\section{REFERENCES}

[1] KOPP, Carlo and Peter GOON. Air Power Australia: Australia's Independent Defence Think Tank. KOPP, Carlo. Russian/Soviet Point Defence Weapons [online]. 2008 [cit. 2015-01-05]. Available from: http://www.ausairpower.net/.

[2] DIEHL BGT DEFENCE. HPEMcarStop: Non-violent system for selective stopping of vehicles in dynamic scenarios [online]. Roethenbach/Pegnitz, Germany, 2013, 4 s. [cit. 2015-01-05]. Available from: http://www.diehl.com/.

[3] DIEHL BGT DEFENCE. White Paper on HPEM Technology [online]. Roethenbach/Pegnitz, Germany, 2013, 14 p. [cit. 2015-01-05]. Available from: http://www.vdi.de/.

[4] DIEHL BGT DEFENCE. HPEMcase: Non-Lethal Effector Systems for the Protection of Persons and Buildings [online]. Roethenbach/Pegnitz, Germany, 2013, 3 p. [cit. 2015-01-05]. Available from: http://www.diehl.com/.

[5] E2V. RF Safe-Stop ${ }^{\mathrm{TM}}$ System: Vehicle stopping technology [online]. Chelmsford, England, 2013, 2 p. [cit. 2015-01-05]. Available from: http://www.e2v.com/.

[6] Eureka Aerospace: Solution to high- tech problems. [online]. 2014 [cit. 2015-01-05]. Available from: http://www.eurekaaerospace.com/.

[7] Non-Lethal Weapons Program: U.S. Department of Defense. [online]. 2014 [cit. 2015-01-05]. Available from: http://jnlwp.defense.gov/.

[8] BERRY, Mark, Todd TURNER a Christian REIFF. Electrical Vehicle Stopper Evaluation: Phase III-Jaycor. Adelphi, USA: U.S. Army Research Laboratory, 2010, ARL-TR-2273. 22 p.

\section{Authors}

Ing. Hana Urbancokova

Ing. Jan Valouch Ph.D.

Ing. Stanislav Kovar

\section{Address:}

Tomas Bata University in Zlin

Faculty of Applied Informatics

nam. T.G.Masaryka 5555, 76001 Zlin

Czech Republic

\section{Emails:}

urbancokova@fai.utb.cz

valouch@fai.utb.cz

skovar@fai.utb.cz 